\title{
Sequencing and characterization of complete mitogenome DNA of Rasbora tornieri (Cypriniformes: Cyprinidae: Rasbora) and its evolutionary significance
}

\author{
HUNG HUI CHUNG ${ }^{1 *}$ (D) , CYNTHIA KERANTI ANAK KAMAR ${ }^{1}$, LEONARD WHYE KIT LIM ${ }^{1 *}$, JILL SELA ROJA ${ }^{1}$, \\ YUNSHI LIAO ${ }^{2}$, TOMMY TSAN-YUK LAM ${ }^{2}$ and YEE LING CHONG $^{3}$ \\ ${ }^{1}$ Faculty of Resource Science and Technology, Universiti Malaysia Sarawak, 94300 Sarawak, Malaysia \\ ${ }^{2}$ School of Public Health, The University of Hong Kong, Sassoon Road, Pokfulam, Hong Kong \\ ${ }^{3}$ Department of Science and Environmental Studies, The Education University of Hong Kong, Tai Po Campus, NT, \\ Hong Kong \\ *For correspondence. E-mail: Hung Hui Chung, hhchung@unimas.my; Leonard Whye Kit Lim, lwk11993@gmail.com.
}

Received 8 October 2019; revised 12 January 2020; accepted 27 April 2020

\begin{abstract}
The yellowtail rasbora (Rasbora tornieri) is a miniature ray-finned fish categorized under the genus Rasbora in the family of Cyprinidae. In this study, a complete mitogenome sequence of $R$. tornieri was sequenced using four primers targeting two halves of the mitogenome with overlapping flanking regions. The size of mitogenome was 16,573 bp, housing 22 transfer RNA genes, 13 protein-coding genes, two ribosomal RNA genes and a putative control region. Identical gene organization was detected between this species and other members of Rasbora genus. The heavy strand encompassed 28 genes while the light strand accommodated the other nine genes. Most protein-coding genes execute ATG as start codon, excluding COI and ND3 genes, which utilized GTG instead. The central conserved sequence blocks (CSB-E, CSB-F and CSB-D), variable sequence blocks (CSB-1, CSB-3 and CSB-2) as well as the terminal associated sequence (TAS) were conserved within the control region. The maximum likelihood phylogenetic family tree revealed the divergence of $R$. tornieri from the basal region of the Rasbora clade, where its evolutionary relationships with other Rasbora members are poorly resolved as indicated by the low bootstrap values. This work acts as window for further population genetics and molecular evolution studies of Rasbora genus in future.
\end{abstract}

Keywords. mitogenome; gene arrangement; light strand origin; phylogeny; Rasbora tornieri.

\section{Introduction}

The yellowtail rasbora (Rasbora tornieri) is categorized under the genus Rasbora within the family Cyprinidae. As its name suggests, this freshwater ray-finned fish is uniquely different from other Rasbora fishes in terms of the striking yellow colouration with broad black margins at its caudal fin (Kottelat et al. 1993). With regard to length, the maximum growth of this fish species can reach up to $17 \mathrm{~cm}$, and they feed on exogenous insects, often spawn in ponds and rivers (Kottelat et al. 1993). It is commonly found in canals and streams of the lowlands and are distributed across Indonesia, Indochina as well as Malaysia (Kottelat et al. 1993).

Cyprinidae family accommodates 11 subfamilies, namely Barbinae, Leuciscinae, Labeoninae, Danioninae (where the yellowtail rasbora resides), Acheilognathinae, Cyprinninae, Cultrinae, Squaliobarbinae, Gobioninae, Tincinae and Xenocypridinae (Liao et al. 2010). The Rasbora group is well-known as 'catch-all' group due to the taxonomical complications known to exist since their discovery contributed by their closely resembled morphological characters (Brittan 1954; Kottelat and Vidthayanon 1993; Siebert and Guiry 1996; Kottelat 2005; Liao et al. 2010; Tang et al. 2010). The most widely known and accepted Rasbora characterization is of Brittan (1954), where the Rasbora sensu lato concept is applied, categorizing them into eight species complexes: pauciperforata, einthovenii, sumatrana-elegans, lateristriata, argyrotaenia, trisfasciata, caudimaculata and daniconius (Brittan 1954). 